\title{
Controlled Functionalization of Multi-Walled Carbon Nanotubes by in situ Atom Transfer Radical Polymerization
}

Hao Kong, Chao Gao*, Deyue Yan*

College of Chemistry \& Chemical Engineering, Shanghai Jiao Tong University, 800 Dongchuan Road, Shanghai 200240, P. R. China.

\section{Supporting Information}

S1. Experimental details

S2. The solubility of the samples

S3. SEM and TEM images of the samples

S4. TGA curves of the samples

S5. ${ }^{1} \mathrm{H}$ NMR and FTIR spectra of the samples

\section{S1. Experimental details}

\section{S1.1. Materials}

MWNT was provided by Tsinghua-Nafine Nano-Powder Commercialization Engineering Centre. Methyl methacrylate (MMA) and hydroxyethyl methacrylate (HEMA) were purchased from Aldrich; the inhibitor was removed by passing a column of alumina and distilling in vacuum. $\mathrm{CuBr}$ was obtained from Aldrich and purified according to the published procedures (Cheng, G.; Böker, A.; Zhang, M.; Krausch, G.; Müller, A. H. E. Macromolecules 2001, 34, 6883.). 2-bromo-2-methylpropionyl bromide ( $\alpha$-bromoisobutyryl bromide), ethyl 2-bromoisobutyrate, thionyl chloride $\left(\mathrm{SOCl}_{2}\right), \mathrm{N}, \mathrm{N}, \mathrm{N}^{\prime}, \mathrm{N}$ ",N"- pentmethyldiethylenetriamine (PMDETA) and $N, N$-dimethylaminopyridine (DMAP) were purchased from Acros and without purification. Tetrahydrofuran (THF), $N, N$-dimethyl formamide (DMF), dimethyl sulfoxide (DMSO), acetone,

${ }^{*}$ Corresponding author. Fax: +86-21-54741297. E-mail: chaogao@sjtu.edu.cn (Gao C), dyyan@sjtu.edu.cn (Yan DY). 
methanol, ethanol, chloroform $\left(\mathrm{CHCl}_{3}\right)$, glycol $\left(\mathrm{HOCH}_{2} \mathrm{CH}_{2} \mathrm{OH}\right)$ and other organic reagents or solvents were obtained from domestic market; they were previously distilled and kept in the presence of $4 \AA$ molecular sieve to eliminate any traces of water before use.

\section{S1.2. Measurements}

Fourier-transform infrared (FTIR) spectra were obtained on a PE Paragon 1000 spectrometer with a disc of $\mathrm{KBr}$. Hydrogen nuclear magnetic resonance ( $\left({ }^{\mathrm{H}} \mathrm{NMR}\right)$ measurements were carried out on a Varian Mercury Plus $400 \mathrm{MHz}$ spectrometer. Ultraviolet-Visible (UV-Vis) spectra were measured on a PE Lambda 20 spectrophotometer. The molecular weight was measured on PE Series 200 gel permeation chromatography (GPC) with PMMA as standards using THF as eluent at the flow rate of $1 \mathrm{~mL} / \mathrm{min}$. Thermal gravimetric analysis (TGA) were carried out on a PE TGA-7 instrument with a heating rate of $20{ }^{\circ} \mathrm{C} / \mathrm{min}$ in the nitrogen flow $(20 \mathrm{~mL} / \mathrm{min})$. Scanning electron microscopy (SEM) images were obtained on a LEO 1550VP field-emission microscope, and the samples were loaded on the glass surface previously sputter-coated with a homogenous gold layer for charge dissipation during the SEM imaging. Transmission electron microscopy (TEM) analysis were conducted on a JEOL JEL2010 electron microscope at $200 \mathrm{kV}$, and the samples for TEM measurements were prepared by placing one drop of sample on copper grids coated with carbon. The photo of the samples placed in solvent was taken with a digital camera (Sony, DSC-S70).

\section{S1.3. Synthesis of MWNT-PMMA and MWNT-PMMA-b-PHEMA}

\section{S1.3.1. Synthesis of MWNT-OH}

Typical procedure (see the scheme below) of fabricating MWNT-OH is described as follows.



Preparation of MWNT-COOH from MWNT. In a typical experiment, $1.0453 \mathrm{~g}$ of crude MWNT were added to $10.0 \mathrm{~mL}$ of $60 \% \mathrm{HNO}_{3}$ aqueous solution. The mixture was treated with ultrasonic bath $(40 \mathrm{kHz})$ for $30 \mathrm{~min}$, and then stirred for $24 \mathrm{~h}$ in reflux. After that, the mixture was vacuum-filtered through $0.22 \mu$ Millipore polycarbonate membrane, and washed with distilled 
water until the $\mathrm{pH}$ value of the filtrate was 7 . The filtered solid was dried under vacuum for $12 \mathrm{~h}$ at $60{ }^{\circ} \mathrm{C}$, giving $0.6104 \mathrm{~g}$ of MWNT-COOH.

Generation of MWNT-COCl from MWNT-COOH. A typical example is given as follows. $0.6104 \mathrm{~g}$ of MWNT-COOH was suspended in $20 \mathrm{~mL}$ of $\mathrm{SOCl}_{2}$. This suspension was stirred at 65 ${ }^{\circ} \mathrm{C}$ for $24 \mathrm{~h}$. The solid was then separated by filtration and washed with anhydrous THF. Subsequently it was dried under vacuum at room temperature for $2 \mathrm{~h}$, obtaining MWNT-COCl $(0.5384 \mathrm{~g})$.

Synthesis of MWNT-OH from MWNT-COCl. Typically, $0.5016 \mathrm{~g}$ sample of as- prepared MWNT-COCl was mixed with $20.0 \mathrm{~mL}$ of glycol and stirred at $120{ }^{\circ} \mathrm{C}$ for $48 \mathrm{~h}$. The solid was separated by vacuum-filtration with $0.22 \mu$ Millipore polycarbonate membrane filter as mentioned above and washed with anhydrous THF. After repeated washing and filtration steps, the resulting solid was dried overnight in vacuum, obtaining MWNT-OH sample (0.4342 g).

\section{S1.3.2. Synthesis of MWNT-Br}

All operations were carried out under nitrogen atmosphere. A sample of MWNT-OH (0.4025 g) was placed in $10.0 \mathrm{~mL}$ of anhydrous $\mathrm{CHCl}_{3} .0 .0292 \mathrm{~g}(0.2390 \mathrm{mmol})$ of DMAP and $0.3031 \mathrm{~g}$ $(1.667 \mathrm{mmol})$ of triethylamine were added. Then $0.3832 \mathrm{~g}(1.667 \mathrm{mmol})$ of 2-bromo-2methylpropionyl bromide dissolved in $5 \mathrm{~mL}$ of anhydrous $\mathrm{CHCl}_{3}$ was added dropwise at $0{ }^{\circ} \mathrm{C}$ in $60 \mathrm{~min}$. The mixture was stirred for $3 \mathrm{~h}$ at $0{ }^{\circ} \mathrm{C}$ followed by stirring at room temperature for $48 \mathrm{~h}$. Then the solid was separated from the mixture by filtration and then washed with $100 \mathrm{~mL}$ of $\mathrm{CHCl}_{3}$ for 5 times. The raw product was re-placed and dispersed in $20 \mathrm{~mL}$ of $\mathrm{CHCl}_{3}$, and the dispersing, filtration and washing steps were repeated three times to remove any adsorbed 2-bromo-2- methylpropionyl bromide. The black filtered solid was collected and dried overnight under vacuum at $40{ }^{\circ} \mathrm{C}$, affording $0.3883 \mathrm{~g}$ of MWNT-Br. The reaction process is described in the following scheme.

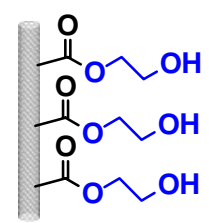

MWNT-OH

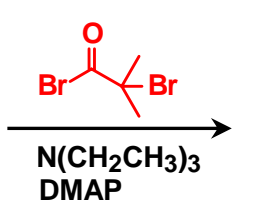

MWNT-Br

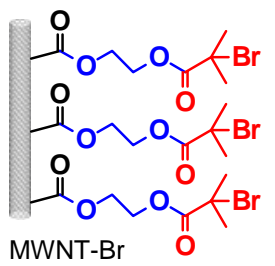

\section{S1.3.3. Synthesis of MWNT-PMMA}

Typically (CP1 in Table 1), $25.2 \mathrm{mg}$ of MWNT-Br, $7.2 \mathrm{mg}(0.050 \mathrm{mmol})$ of $\mathrm{CuBr}, 8.7 \mathrm{mg}$ $(0.050 \mathrm{mmol})$ of PMDETA and $0.25 \mathrm{~mL}$ of DMF were placed in a $10 \mathrm{~mL}$ dried flask and then the 
flask was sealed with a rubber plug. The flask was evacuated and back-filled with Ar-gas three times. After this procedure $25.6 \mathrm{mg}(0.255 \mathrm{mmol})$ of MMA was injected into the flask using a syringe. The flask was immersed in an oil bath at $60{ }^{\circ} \mathrm{C}$ immediately and kept stirring for $20 \mathrm{~h}$. At the end of the reaction the viscosity had increased dramatically. The mixture was diluted with $\mathrm{CHCl}_{3}$ and vacuum-filtration with $0.22 \mu$ Millipore polycarbonate membrane filter for three times. To ensure that no any possible un-grafted polymer and free reagents were mixed in the product, in each time, the filter mass was dispersed in $\mathrm{CHCl}_{3}$, then filtered and washed with $\mathrm{CHCl}_{3}$. The resulting solid was redispersed in $5 \mathrm{~mL}$ of $\mathrm{CHCl}_{3}$ and precipitated in $100 \mathrm{~mL}$ of methanol. The MWNT-PMMA (CP1) was obtained by filtration and drying overnight under vacuum.

${ }^{1} \mathrm{H}$ NMR $\left(\mathrm{CDCl}_{3}\right)$ (ppm): $3.56\left(-\mathrm{OCOCH}_{3}\right), 1.77\left(\mathrm{C}-\mathrm{CH}_{2}-\mathrm{C}\right), 0.75 \sim 0.92\left(-\mathrm{CH}_{3}\right)$.

IR $\left(\mathrm{KBr}, \mathrm{cm}^{-1}\right): 1734(\mathrm{C}=\mathrm{O}), 1630 \sim 1662(\mathrm{C}=\mathrm{C}), 1436 \sim 1483 \quad\left(-\mathrm{CH}_{3}\right), 1245 \sim 1270 \quad(\mathrm{C}-\mathrm{O})$, 1147 1190 (C-C).

\section{S1.3.4. Synthesis of MWNT-PMMA-b-PHEMA}

The MWNT-PMMA- $b$-PHEMA (CP5) was fabricated via in situ ATRP of HEMA initiated by the active $\mathrm{Br}$ atoms at the end of polymer chains on MWNT-PMMA (see the following scheme).

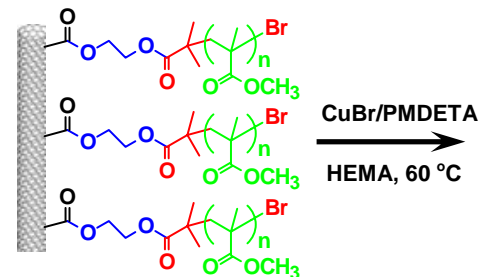

MWNT-PMMA

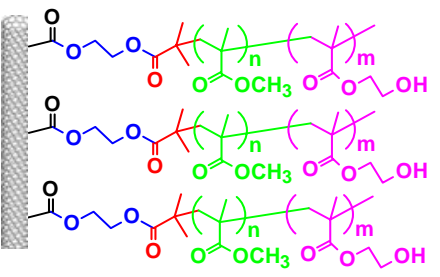

MWNT-PMMA-b-HEMA

$25.3 \mathrm{mg}$ of CP1 (in Table 1), $5.7 \mathrm{mg}(0.040 \mathrm{mmol})$ of $\mathrm{CuBr}, 7.0 \mathrm{mg}(0.040 \mathrm{mmol})$ of PMDETA and $0.25 \mathrm{~mL}$ of DMF were placed in a $10 \mathrm{~mL}$ flask and the flask was sealed with a rubber plug. The flask was evacuated and back-filled with Ar-gas three times. After this procedure $25.4 \mathrm{mg}$ (0.195 mmol) of HEMA was injected into the flask using a syringe. The flask was immersed in an oil bath at $60{ }^{\circ} \mathrm{C}$ immediately and kept stirring for $20 \mathrm{~h}$. At the end of the reaction the viscosity had increased dramatically. The mixture was diluted with DMF and vacuum-filtration with $0.22 \mu$ Millipore polycarbonate membrane filter for three times. To ensure that no any possible un-grafted polymer and free reagents were mixed in the product, in each time, the filter mass was dispersed in DMF, then filtered and washed. The resulting solid was dispersed in $5 \mathrm{~mL}$ of DMF and precipitated in $100 \mathrm{~mL}$ of ether. The MWNT-PMMA-b-PHEMA (CP5) was obtained by filtration and drying overnight under vacuum. 
${ }^{1} \mathrm{H}$ NMR (DMSO) (ppm): 4.79 (-OH), $3.88\left(\mathrm{COOCH}_{2}-\mathrm{CH}_{2} \mathrm{OH}\right), 3.56\left(-\mathrm{OCH}_{2}-\mathrm{CH}_{2} \mathrm{OH}, \mathrm{COOCH}_{3}\right.$, overlapped), $1.77\left(\mathrm{C}-\mathrm{CH}_{2}-\mathrm{C}\right), 0.75 \sim 0.92\left(-\mathrm{CH}_{3}\right)$.

IR $\left(\mathrm{KBr}, \mathrm{cm}^{-1}\right): 3300-3700(-\mathrm{OH}), 1734(\mathrm{C}=\mathrm{O}), 1630 \sim 1662(\mathrm{C}=\mathrm{C}), 1436 \sim 1483 \quad\left(-\mathrm{CH}_{3}\right)$, 1245 1270 (C-O), 1147 1190 (C-C).

\section{S1.4. Synthesis of PMMA via ATRP}

The ATRP polymerization of MMA was carried out in solution which was comparable to the synthesis of WMNT-PMMA. To a dry flask, typically, $14.3 \mathrm{mg}(0.1 \mathrm{mmol})$ of $\mathrm{CuBr}, 17.3 \mathrm{mg}$ (0.1 mmol) of PMDETA, $0.9 \mathrm{~mL}$ of anhydrous DMF and $1 \mathrm{~g}$ of MMA (10 mmol) were added and the flask was sealed with a rubber plug. The flask was evacuated and back-filled with Ar-gas three times. After this procedure, $19.5 \mathrm{mg}(0.1 \mathrm{mmol})$ of ethyl 2-bromoisobutyrate dissolved in $0.1 \mathrm{~mL}$ of DMF was injected into the flask using a syringe. The flask was immersed in an oil bath at $60{ }^{\circ} \mathrm{C}$ immediately and kept stirring for $20 \mathrm{~h}$. At the end of the reaction the viscosity had increased dramatically. The polymer was isolated by dissolving in $\mathrm{CHCl}_{3}$ and passing through a column of alumina and then isolated by precipitation into cold methanol. Three samples with different $M_{\mathrm{n}} \mathrm{s}$ were prepared. The reaction conditions and results are summarized in the following table.

Table S1-1. The reaction conditions and results for ATRP of MMA.

\begin{tabular}{cccccc}
\hline Code & {$[\mathrm{M}] /[\mathrm{I}] /[\mathrm{CuBr}] /[\mathrm{PMDETA}]^{\mathrm{a}}$} & Yield $(\%)$ & $M_{\mathrm{n}, \mathrm{GPC}}$ & $M_{\mathrm{w}} / M_{\mathrm{n}}$ & $\mathrm{DP}^{\mathrm{b}}$ \\
\hline PMMA1 & $50: 1: 1: 1$ & 50 & 3,500 & 1.38 & 35 \\
PMMA1 & $100: 1: 1: 1$ & 65 & 7,800 & 1.46 & 78 \\
PMMA3 & $200: 1: 1: 1$ & 60 & 12,700 & 1.25 & 127 \\
\hline
\end{tabular}

${ }^{\text {a }}$ monomer : initiator (ethyl 2-bromoisobutyrate) : CuBr : PMDETA (mol : mol : mol : mol). The reaction time is $20 \mathrm{~h}$, and the reaction temperature is $60^{\circ} \mathrm{C}$. ${ }^{\mathrm{b}}$ degree of polymerization of PMMA.

Table S1-1 showed that the molecular weight of the resulting polymers can be controlled by the ATRP in our experiments.

\section{S1.5. ATRP of MMA in the presence of MWNT-COOH}

The procedure was the similar to that described in S1.3.3 by using ethyl 2-bromoisobutyrate as initiator $([\mathrm{M}] /[\mathrm{I}] /[\mathrm{CuBr}] /[\mathrm{PMDETA}]=100: 1: 1: 1$ in moles, the weight ratio of MWNT-COOH to MMA is $1 / 5)$.

$200.2 \mathrm{mg}$ of MWNT-COOH, $14.3 \mathrm{mg}(0.10 \mathrm{mmol})$ of $\mathrm{CuBr}, 17.3 \mathrm{mg}(0.10 \mathrm{mmol})$ of PMDETA, $1.0010 \mathrm{~g}(10 \mathrm{mmol})$ of MMA and $1 \mathrm{~mL}$ of DMF were placed in a flask and the flask was sealed 
with a rubber plug. The flask was evacuated and back-filled with Ar-gas three times. After this procedure $19.5 \mathrm{mg}(0.10 \mathrm{mmol})$ of ethyl 2-bromoisobutyrate was injected into the flask using a syringe. The flask was immersed in an oil bath at $60{ }^{\circ} \mathrm{C}$ immediately and left under stirring for 20 h. At the end of the reaction the viscosity had increased dramatically. The mixture was diluted with $\mathrm{CHCl}_{3}$ and vacuum-filtration with $0.22 \mu$ Millipore polycarbonate membrane. The solid was re-placed and dispersed in $20 \mathrm{~mL}$ of $\mathrm{CHCl}_{3}$, and the dispersing, filtration and washing steps were repeated three times. The resulting solid was collected and dried overnight under vacuum at $50{ }^{\circ} \mathrm{C}$. $193 \mathrm{mg}$ of black solid (the sample was called as CM1 in the paper) was obtained. The polymer in the filtrate was isolated by passing through a column of alumina then isolated by precipitation into cold methanol. The molecular weight $\left(M_{\mathrm{n}}\right)$ and its distribution $\left(M_{\mathrm{w}} / M_{\mathrm{n}}\right)$ of the resultant PMMA measured by GPC are 6,700 and 1.56, respectively.

The measurements of TGA and TEM showed that no polymer was found in the sample of CM1. The TGA curve and TEM image of CM1 are very similar to those of MWNT-COOH. So the PMMA mixed in the system of functionalized MWNT can be efficiently removed by the washing method mentioned above.

\section{S1.6. Mixing PMMA with MWNT-COOH}

To compare with the properties of MWNT-PMMA, two mechanical blended samples of PMMA and MWNT-COOH were also fabricated. Generally, proportional MWNT-COOH, PMMA3 and $\mathrm{CHCl}_{3}$ were added to a flask and stirred at $60{ }^{\circ} \mathrm{C}$ for 20 hours. Then $\mathrm{CHCl}_{3}$ was evaporated under $80{ }^{\circ} \mathrm{C}$ and dried in vacuum. The mixed theory content $\left(f_{\mathrm{w} t \text {,mix }}\right)$ and the content calculated from the result of TGA $\left(f_{\mathrm{wt}, \text { TGA }}\right)$ of PMMA3 in the composites were given in Table S1-2.

Table S1-2. The content of polymer in the mixed samples.

\begin{tabular}{cccc}
\hline Code & MWNT-COOH:PMMA3 (wt:wt) & $f_{w t, m i x}(\%)$ & $f_{w t, T G A}(\%)^{\mathrm{a}}$ \\
\hline CM2 & $2: 1$ & 33.3 & 31.6 \\
CM3 & $1: 2$ & 66.7 & 64.9 \\
\hline
\end{tabular}

${ }^{\mathrm{a}}$ The lost weight content between 210 and $425^{\circ} \mathrm{C}$. 


\section{S2. The solubility of the samples}

The solubility of the samples was summarized in Table S2-1, and a photo of the sample placed in solvent was given in Figure S2-1.

Table S2-1. Solubility of the samples ${ }^{\mathrm{a}}$.

\begin{tabular}{|c|c|c|c|c|c|c|c|c|c|c|}
\hline Code & $\mathrm{H}_{2} \mathrm{O}$ & $\mathrm{Et}-\mathrm{OH}$ & DMF & DMSO & acetone & ether & toluene & Et-OAc & THF & $\mathrm{CHCl}_{3}$ \\
\hline MWNT & - & - & - & - & - & - & - & - & - & - \\
\hline WMNT-COOH & \pm & - & - & - & - & - & - & - & - & - \\
\hline MWNT-OH & - & \pm & \pm & \pm & - & - & - & - & - & \pm \\
\hline MWNT-Br & - & + & + & + & + & + & + & + & + & + \\
\hline CP1-CP4 & - & \pm & \pm & \pm & + & + & + & + & + & + \\
\hline CP5 & - & - & + & + & - & - & - & - & - & - \\
\hline CM1 & \pm & - & - & - & - & - & - & - & - & - \\
\hline
\end{tabular}

a “_”, “士”" and "“+” denote "insoluble”, "partially soluble” and "soluble”, respectively.

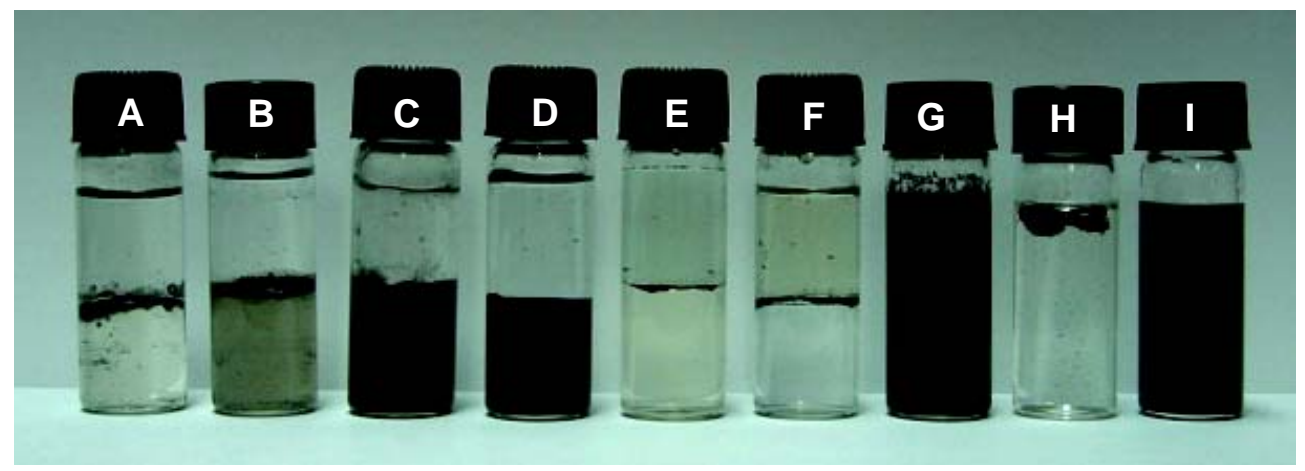

Figure S2-1. A photo of the samples placed in solvents (the upper solvent of A, B, C, D, E, $\mathrm{F}$ is water, and the lower solvent is $\mathrm{CHCl}_{3}$ ). A: MWNT-COOH, B: MWNT-OH, C: MWNT-Br, D: CP3, E: CM1, F: CM3, G: CP3 in $\mathrm{CHCl}_{3}, \mathrm{H}$ : CP5 in $\mathrm{CHCl}_{3}$, I: CP5 in DMF. The content of the sample is around $1.25 \mathrm{mg}$ of sample per $1 \mathrm{~mL}$ of solvent.

The crude MWNT was insoluble in any solvents tested. After oxidation of MWNT with $\mathrm{HNO}_{3}$, polar carboxyl groups were introduced into the convex surface of MWNT, so MWNT-COOH was partially soluble in water. If the MWNT-COOH was placed firstly in $\mathrm{CHCl}_{3}$, followed by adding water to the mixture, MWNT-COOH would move to the water phase and aggregated on the interface of water and $\mathrm{CHCl}_{3}$. MWNT-OH showed some extent of solubility in $\mathrm{CHCl}_{3}$ and polar solvents such as DMF and DMSO, and MWNT-Br showed relatively good solubility in polar 
solvents and non-polar solvents. The MWNT-PMMA samples showed good solubility in nonpolar solvents and poor solubility in polar solvents. Compared with the MWNT-PMMA, MWNT-PMMA-b-PHEMA was only soluble in strong polar solvents such as DMF and DMSO because of its strong polar PHEMA chains. The solubility of CM1 and CM3 (black solid section of $\mathrm{CM} 3$ ) is very similar to that of MWNT-COOH, and completely different from that of MWNT-PMMA. The compared solubility of the samples aforementioned gives qualitative and direct evidence for the conclusions that the ATRP initiator is covalently linked to the carbon nanotubes, the PMMA is covalently grafted onto the MWNT in the samples of MWNT-PMMA, and PHEMA is covalently linked with MWNT-PMMA in the sample of CP5 (MWNT-PMMA-b-PHEMA).

It is notable that the "soluble" mentioned above represents the solid sample can be well dispersed in a solvent, forming a stable, clear and transparent system.

The solubility and dispersibility of the resultant samples were further semi-quantitatively characterized with UV-Vis spectrophotometer. The absorbance (A) of MWNT- $\mathrm{Br}$ in $\mathrm{CHCl}_{3}$ is much higher than that of MWNT-OH or MWNT-COOH. The absorbance of MWNT-PMMA in $\mathrm{CHCl}_{3}$ is significantly greater than that of CM1, CM3, or MWNT-COOH, while the absorbance of CM1 or CM3 is almost equal to that of MWNT-COOH. In addition, the absorbance of CP5 in DMF is much higher than that of $\mathrm{CP} 5$ in $\mathrm{CHCl}_{3}$. The absorbance values at $600 \mathrm{~nm}\left(\mathrm{~A}_{600}\right)$ of the samples were given in Table S2-2.

Table S2-2. The absorbance at $600 \mathrm{~nm}\left(\mathrm{~A}_{600}\right)$ of the samples with a content of $1 \mathrm{mg}$ sample per $10 \mathrm{~mL}$ solvent (the solvent is $\mathrm{CHCl}_{3}$ except the marked one).

\begin{tabular}{lllllllll}
\hline Item & $\begin{array}{l}\text { MWNT } \\
-\mathrm{COOH}\end{array}$ & $\begin{array}{l}\text { MWNT } \\
-\mathrm{OH}\end{array}$ & $\begin{array}{l}\text { MWNT } \\
-\mathrm{Br}\end{array}$ & $\mathrm{CP3}$ & $\mathrm{CM} 1$ & $\mathrm{CM} 3$ & $\mathrm{CP5}$ & $\begin{array}{l}\mathrm{CP} 5 \text { in } \\
\text { DMF }\end{array}$ \\
\hline $\mathrm{A}_{600}$ & 0.0293 & 0.138 & 0.684 & 0.369 & 0.0299 & 0.0305 & 0.0411 & 0.218 \\
$R_{600}{ }^{\mathrm{a}}$ & 1.00 & 4.71 & 23.34 & 12.59 & 1.02 & 1.04 & 1.40 & - \\
\hline
\end{tabular}

${ }^{\mathrm{a}}$ the ratio of $\mathrm{A}_{600}$ of the sample to $\mathrm{A}_{600}$ of MWNT-COOH. 


\section{S3. SEM and TEM images of the samples}

\section{S3.1. SEM images}

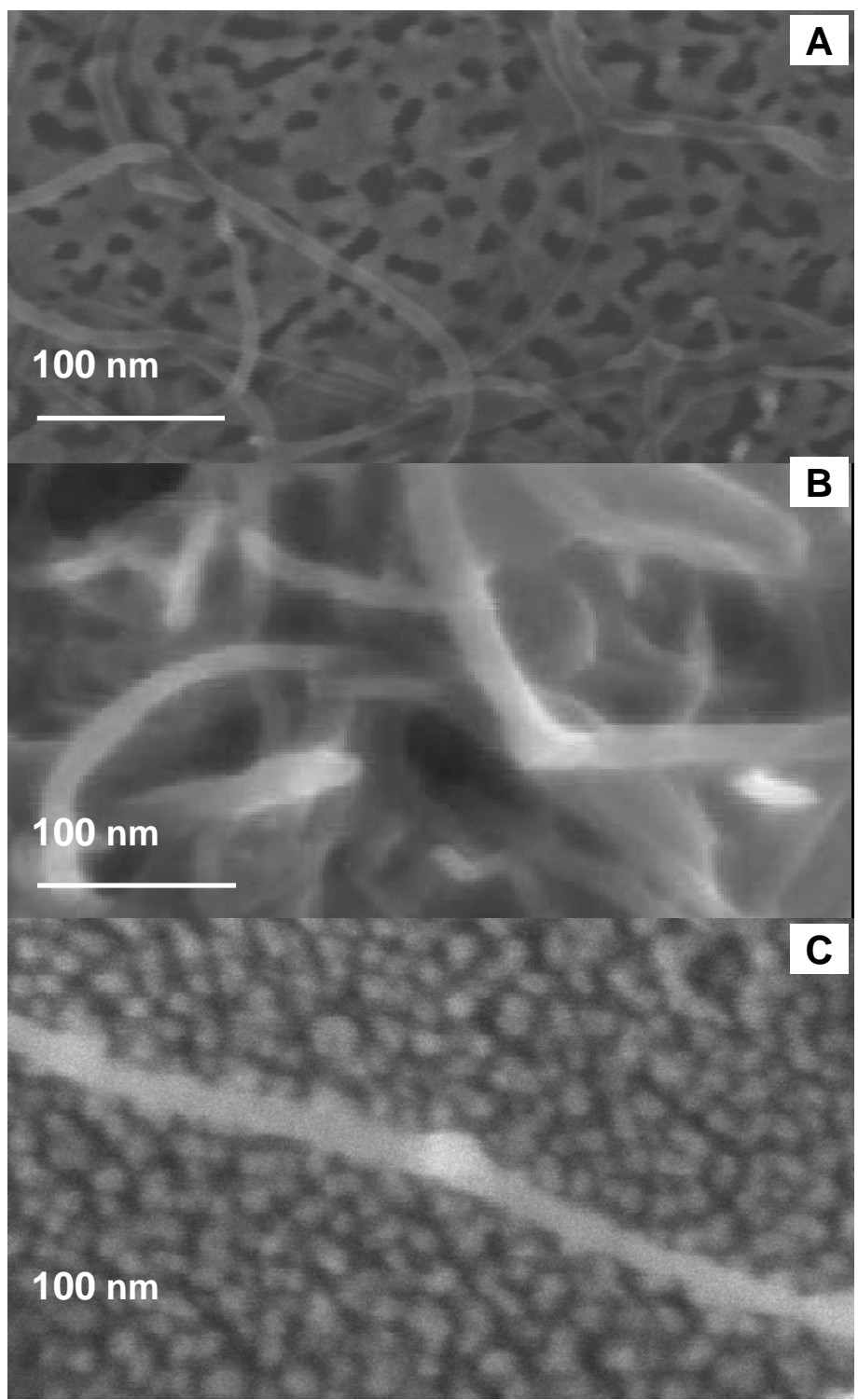

Figure S3-1. SEM images of crude MWNT $(A)$ and CP2 (B, C). 
S3.2. TEM images of the crude MWNT and the resulting functionalized MWNT

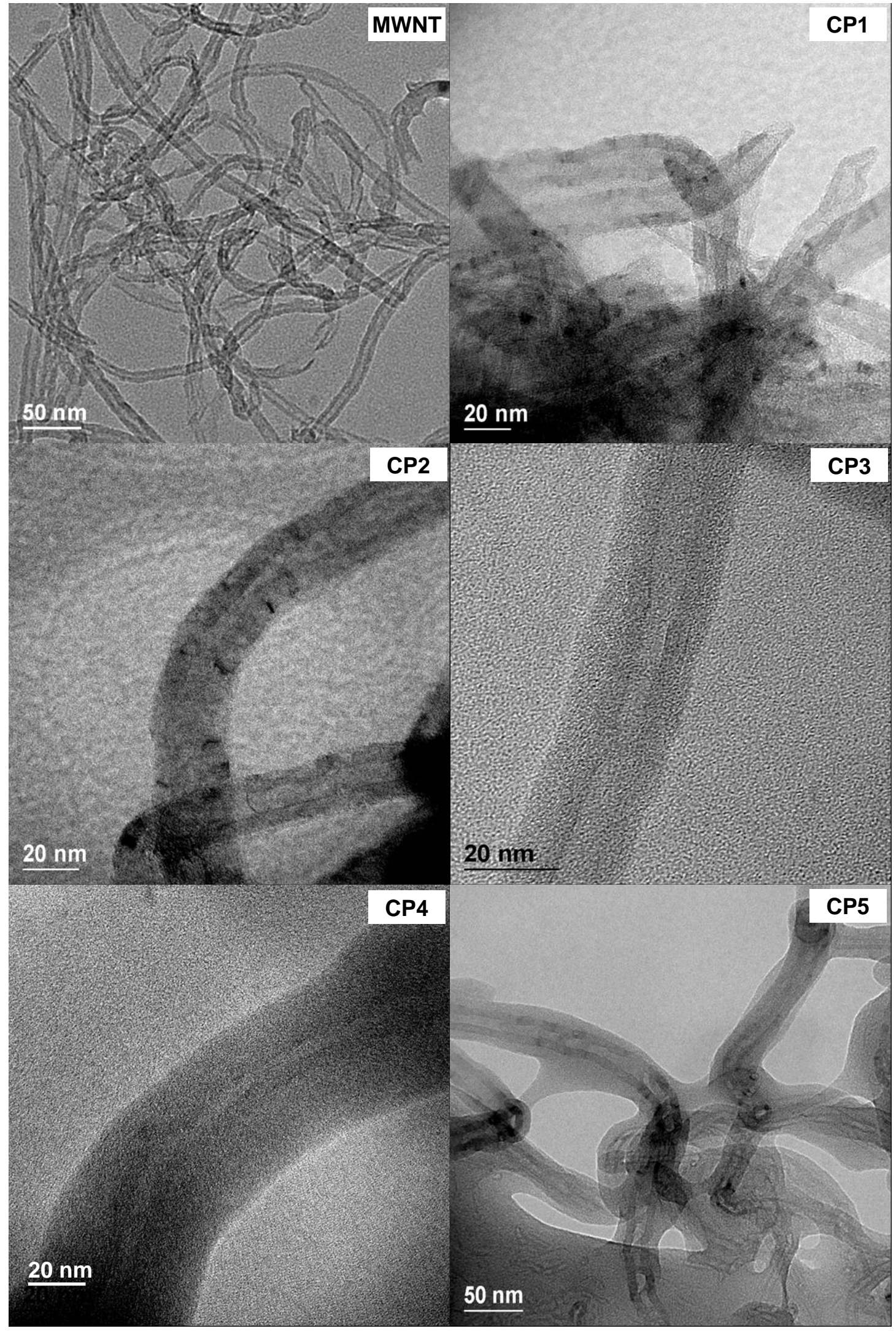

Figure S3-2. TEM images of the crude MWNT and the resulting functionalized MWNT. 


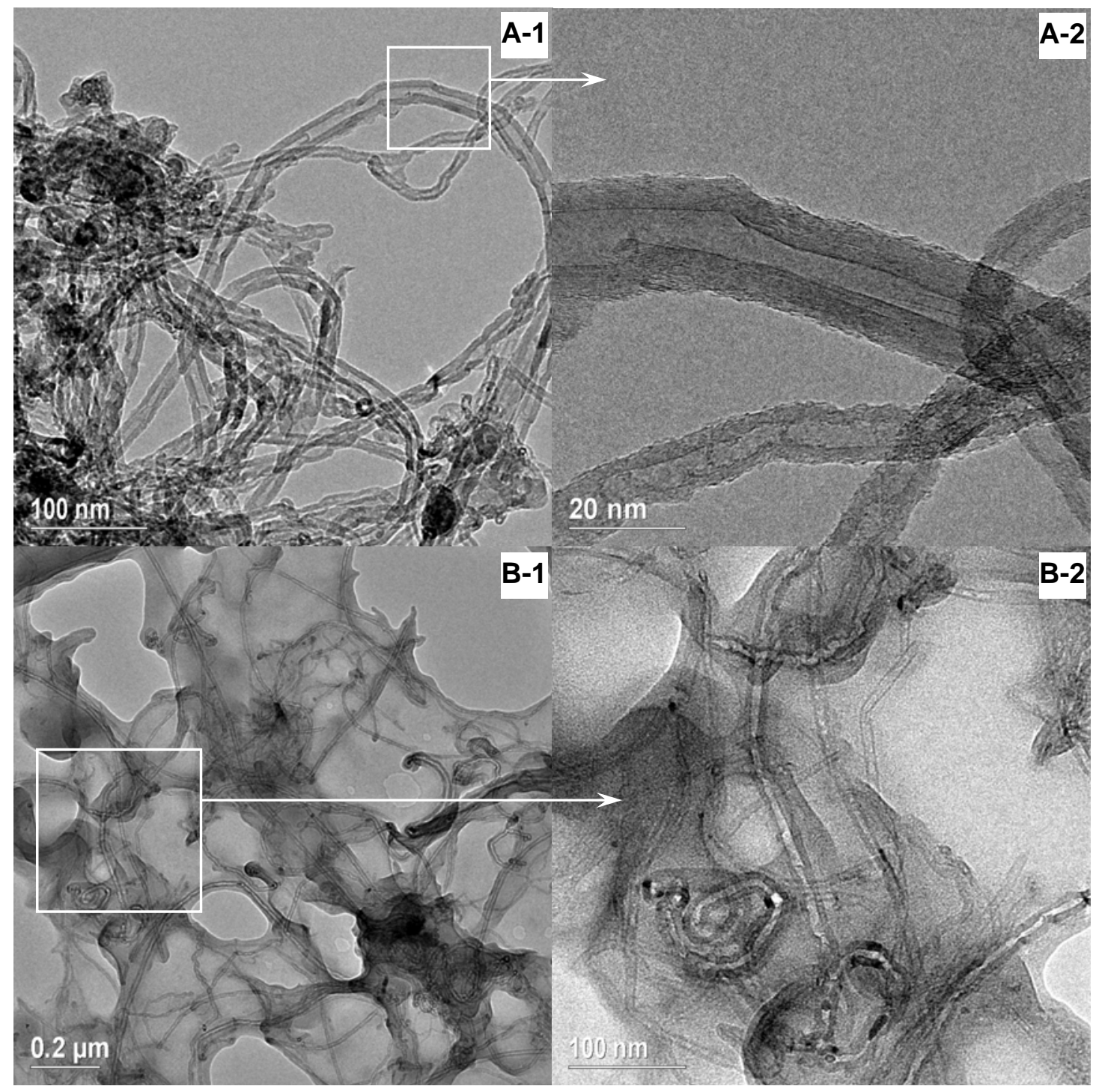

Figure S3-3. TEM images of CM1 (A-1, A-2) and CM3 (B-1, B-2).

Figure S3-3 showed that no polymer layers were observed in the image of CM1. In the image of $\mathrm{CM} 3$, the continuous polymer phase was just mechanically blended in the whole system, and those carbon nanotubes enwrapped with polymer layers being similar to that of MWNT-PMMA can be hardly found. 
S4. TGA curves of the samples



Figure S4-1. TGA curves of the crude MWNT and functionalized MWNT.

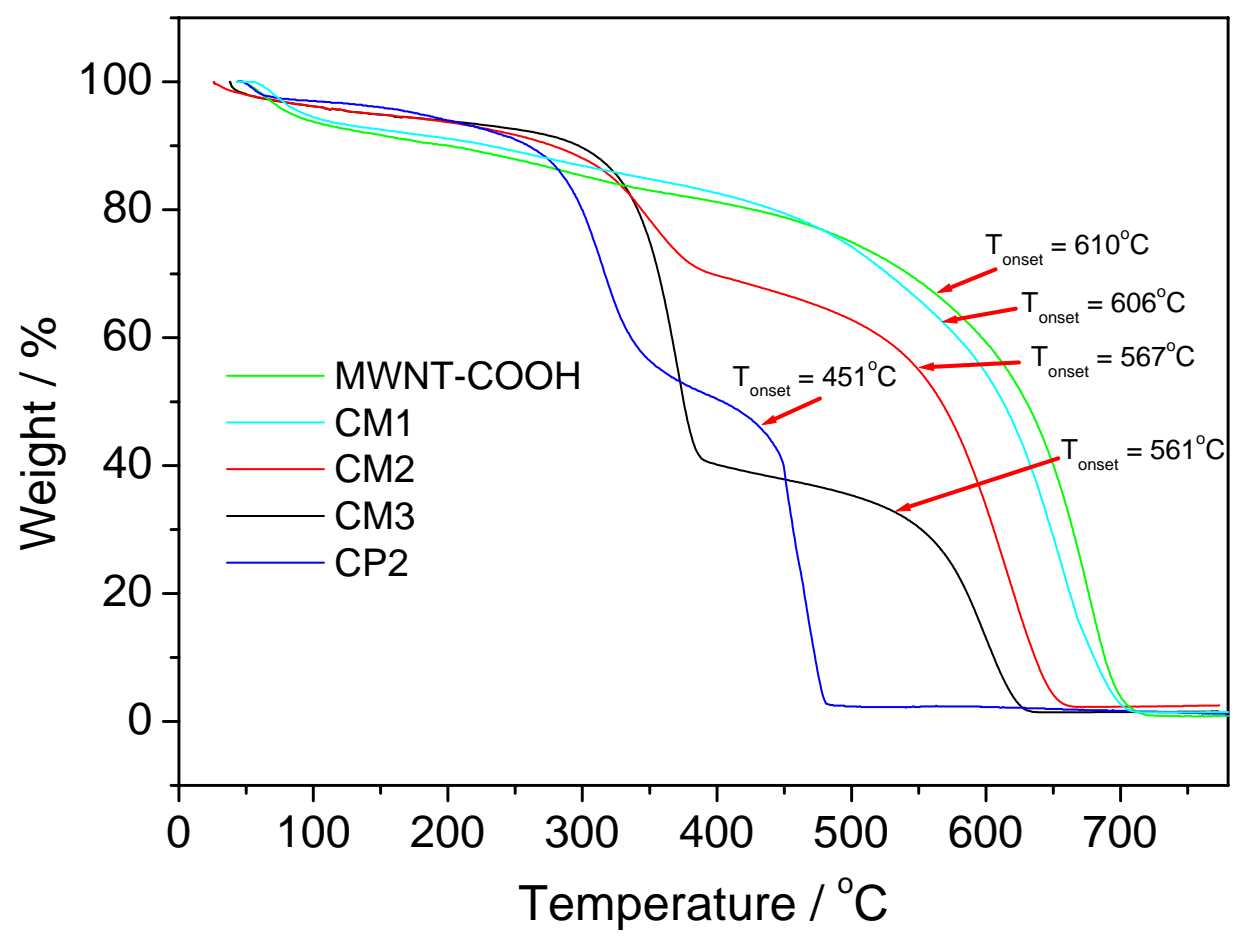

Figure S4-2. TGA curves of MWNT-COOH, CM1, CM2, CM3 and CP2. 
As shown in Figure S4-1, the sample of crude MWNT is steady without significant weight loss below $600{ }^{\circ} \mathrm{C}$. On the contrary, the sample of MWNT-COOH decomposes slowly with the increasing of temperature likely because of the losing of carboxyl groups on the surface of MWNT. For the sample of polymer grafted MWNT (CP1-CP5), three main weight-loss regions are found. The first weight-loss region below $\sim 200{ }^{\circ} \mathrm{C}$ can be assigned to the decomposition of free carboxyl groups on the surface of MWNT. The rapid weight decrease in the second region ( $\sim 200-380{ }^{\circ} \mathrm{C}$, the onsets are at $\sim 300{ }^{\circ} \mathrm{C}$ ) may readily be attributed to the decomposition of PMMA and PHEMA polymers. The significant weight reduction in the third region $\left(\sim 380-500{ }^{\circ} \mathrm{C}\right.$, onsets are at $\sim 450{ }^{\circ} \mathrm{C}$ ) is likely due to the decomposition of MWNT. In addition, the decomposition temperature of MWNT core of MWNT-PMMA (onset is $\sim 450{ }^{\circ} \mathrm{C}$ ) is lower by about $150-200{ }^{\circ} \mathrm{C}$ than that of MWNT-COOH.

As displayed in Figure S4-2, the TGA curve of CM1 is very similar to that of MWNT-COOH, and no polymer weight loss region can be detected, which indicates that the adsorbed polymer can be almost completely removed from the system of CM1 by the washing method described in this paper. Compared with the TGA curve of CP2, the blended samples (CM2 and CM3) exhibit much higher decomposition temperature $\left(\sim 110^{\circ} \mathrm{C}\right)$ in the third weight loss region, which suggests that the covalent grafted polymer has dramatic influence on the thermostability of MWNT.

It seems that at least two factors may influence the thermostability of the nanotubes. Firstly, the oxygenous units and other fragments generated by decomposition of functionalized moieties or mixed organic compounds would lower the decomposition temperatures of nanotubes because part of these fragments can couple with some outer layer carbons of nanotubes and thus destroyed the relatively "perfect" structure of tubes. So the weight loss onsets of nanotubes in MWNT $(\sim 626$ $\left.{ }^{\circ} \mathrm{C}\right)$, MWNT-COOH $\left(\sim 610^{\circ} \mathrm{C}\right), \mathrm{CM} 2\left(\sim 567{ }^{\circ} \mathrm{C}\right)$ and $\mathrm{CM} 3\left(\sim 561{ }^{\circ} \mathrm{C}\right)$ decreased with increasing the contents of functionalized moieties and mixed polymers. Secondly, the graft of PMMA on the convex surface of MWNT had exfoliated the individual nanotube from the usual carbon nanotube ropes and thus lowered remarkably the decomposition temperature of the tubes. Hence, the decomposition temperature of nanotubes in the samples of polymer grafted MWNT-PMMA is lower by about $100-150{ }^{\circ} \mathrm{C}$ than that of nanotubes in the mixed polymer samples of CM2 and $\mathrm{CM} 3$, and lower by about $150-200{ }^{\circ} \mathrm{C}$ than that of samples without any grafted or mixed polymers (MWNT-COOH, MWNT-OH and MWNT-Br). 
S5. ${ }^{1} \mathrm{H}$ NMR and FTIR spectra of the samples

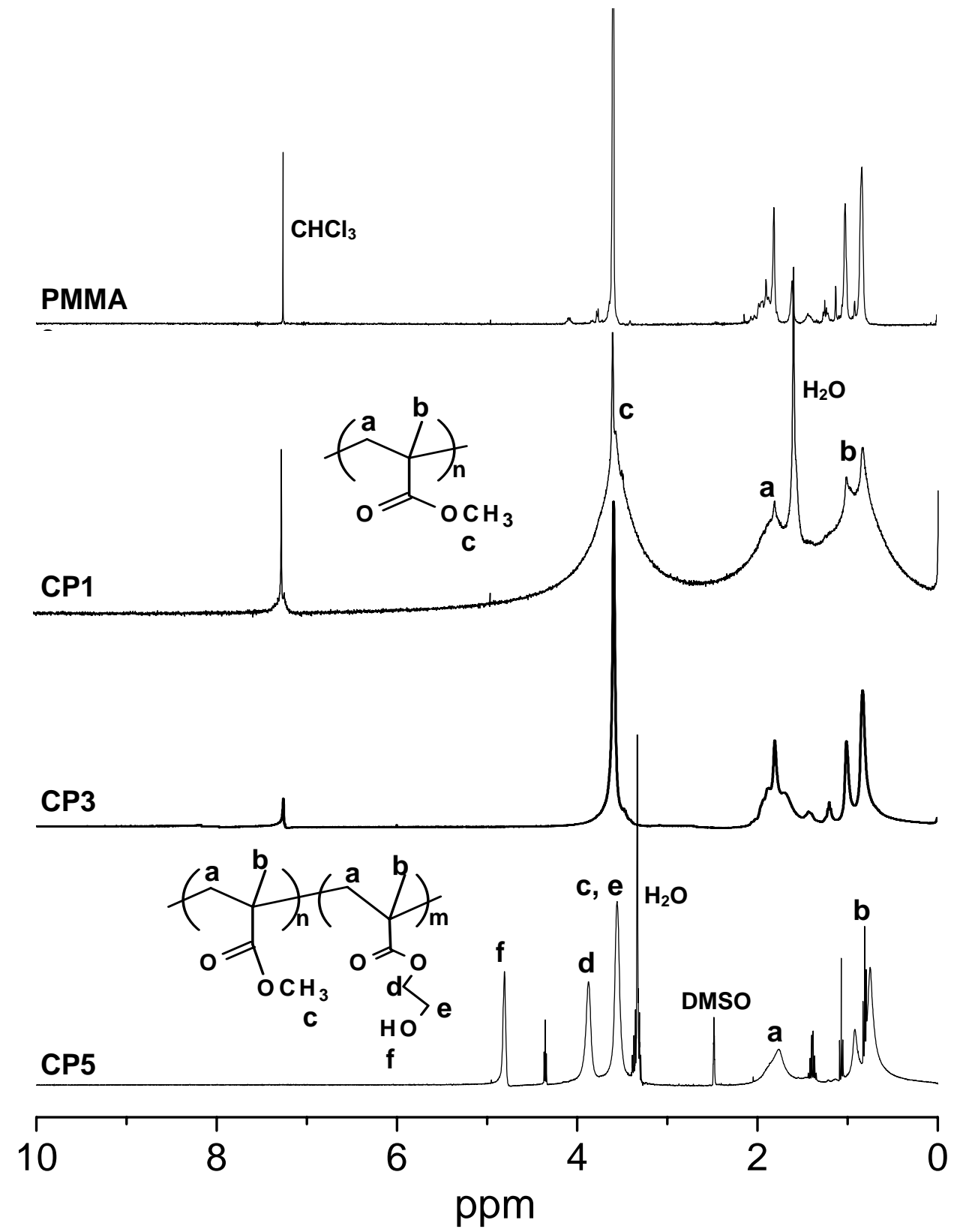

Figure S5-1. ${ }^{1} \mathrm{~N}$ NMR spectra of PMMA3 $\left(\mathrm{CDCl}_{3}\right), \mathrm{CP} 1\left(\mathrm{CDCl}_{3}\right), \mathrm{CP} 3\left(\mathrm{CDCl}_{3}\right)$ and $\mathrm{CP} 5$ (DMSO- $\left.d_{6}\right)$. 




Figure S5-2. FTIR spectra of MWNT (A), MWNT-COOH (B), CM1 (C), MWNT-OH (D), MWNT-Br (E) and CP1 (F).

As displayed in Figure S5-2, the absorption signal of carbonyl band at around $1730 \mathrm{~cm}^{-1}$ is hardly detected for the crude MWNT, clearly observed for the sample MWNT-Br, and strongly found for MWNT-PMMA with respect to the $\mathrm{C}=\mathrm{C}$ absorption band around $1660 \mathrm{~cm}^{-1}$. The FTIR spectra are full in agreement with the fact that the carbonyl bonds of MWNT-Br and MWNT-PMMA are higher than those of their corresponding precursors. Furthermore, the FTIR spectrum of CM1 is very similar to that of MWNT-COOH, and no obvious increase of carbonyl absorption can be found in the spectrum of CM1. This data further indicates that no PMMA was grafted or mixed in the sample of CM1. 